\title{
A Study on the Development Ability of Economic Zones Above Provincial Level in Anhui Province -Based on Principal Component Analysis
}

\author{
Yu Lei ${ }^{1, a}$, Tao Youtian ${ }^{2, b^{*}}$ \\ ${ }^{12}$ School of Business Administration, Chaohu University, Chaohu, 238000, China
}

\begin{abstract}
This paper uses the principal component analysis method to measure the output capacity, input capacity and comprehensive development capacity of development zones in 2017, taking nine indicators reflecting the economic development capacity of 11 development zones above the provincial level in Anhui Province as the research object. The results show that the development level of 11 development zones in Anhui Province is not high on the whole, and the output capacity and comprehensive development capacity show a trend of polarization; the input capacity has three obvious levels, and the location advantage plays an important role in the development o economic zones.
\end{abstract}

\section{INTRODUCTION}

A new round of scientific and technological revolution and industrial transformation are ready to take place in the world. The industrial pattern of China and the global economy is undergoing profound changes. The development environment of the development zone will face major changes, as will the development zone of Anhui Province. In this context, it is necessary to further study the development mode of the development zone and promote the transformation and upgrading of the development zone. Zhang La (2015) used the method of factor analysis to analyze and study the statistical data of each high-tech Industrial Development Zone in Hubei Province, extracted four common factors such as industrial development scale, industrial development environment, enterprise innovation ability and industrial development speed, and comprehensively ranked and classified the development level of each high-tech Industrial Development Zone based on the ranking of factor scores [1]. Lei Shuguang (2017) compared the performance ranking of Shanghai Development Zone from 2009 to 2015, and found that: the leading industrial parks in innovation, resource utilization efficiency and other aspects are often able to achieve faster development and gradually catch up with other parks, while the development of industrial parks dominated by traditional industries is relatively lagging behind. To promote innovation and improve the efficiency of resource utilization is an important focus of the transformation and development of Shanghai Industrial Park at this stage [2]. Some scholars have also studied the development ability of Anhui development zone. Wang Chengjiang (2013) took 117 economic and technological development zones in Anhui Province as research samples, used principal component analysis to comprehensively evaluate the development potential of economic and Technological Development in newly upgraded countries, and found that economic scale factor, intensive efficiency factor, location advantage factor and industrial enterprise development strength factor are the main factors affecting the development potential of newly upgraded national economic and technological development zones [3]. Zhang Heng and Guo ya (2013) studied the development trend of some economic development zones in Anhui Province by using the time series global principal component analysis method, and found that the development trend of each economic development zone was related to the macro-economic environment, policy measures and regional development differences in Anhui Province [4]. Cao Chenglong (2018) comprehensively evaluated and ranked the development level of development zones belonging to 16 cities by using the method of Di value weighting. The results showed that the ranking of each city over the years was relatively stable, but the development level gap was obvious [5]. Wang Xiaomeng (2018) based on the achievements of development zones above the provincial level in 16 cities of Anhui Province, constructed a development evaluation index system and used the principal component analysis method in quantitative economics for comprehensive evaluation. Put forward the countermeasures to speed up the development, namely: give full play to the leading radiation function of the provincial capital urban development zone, cultivate the new development function of the Development Zone, strengthen the guarantee of human resources, increase the government's support for the Development Zone, and do a good job in the development monitoring and evaluation of the Development Zone [6]. The above research obviously has certain reference value, but in the 
face of the changes in the international and domestic economic environment, it is necessary to study and judge the development ability of Anhui Development Zone, which is conducive to the targeted transformation and upgrading of the development zone.

\section{RESEARCH METHODS AND VARIABLE SELECTION}

\subsection{Research methods}

The research method used in the thesis is factor analysis. The factor analysis method is an analysis method for evaluating abstract factors based on explicit variables, that is, specific indicators. It was first proposed by

$$
\left(\begin{array}{l}
x_{1}=a_{11} F_{1}+a_{12} F_{2}+\cdots+a_{1 m} F_{m}+\beta_{1} \xi_{1} \\
x_{2}=a_{21} F_{1}+a_{22} F_{2}+\cdots+a_{2 m} F_{m}+\beta_{2} \xi_{2} \\
x_{p} \\
x_{p 1} F_{1}+a_{p 2} F_{2}+\cdots+a_{p m} F_{m}+\beta_{p} \xi_{p}
\end{array}\right)
$$

In the formula, $x_{1}, x_{2} \cdots x_{p}$ is an original variable $p$, Is a standardized scalar with a mean value of 0 and a standard deviation of $1 ; F_{1}, F_{2} \cdots F_{m}$ are Common factor of original variable, $m \prec p, \xi_{1}, \xi_{2} \cdots \xi_{p}$ are Special factor of original variable, Common factor ${ }^{F_{i}}$ and Special factor $\xi_{i}$ Are independent variables, And the normal ones are $N\left(0, \delta^{2}\right)$; The matrix $a_{p m}$ is factor load, Its elements $a_{i j}$ Represents the load of the sub $i$ variable on the $j$ main factor. The matrix expression of the factor analysis model is:

$$
X=A F+\beta \xi(2)
$$

\subsection{Variable selection and Data source}

According to the relevant literature, the first level indicators of comprehensive development capacity of development zones above the provincial level in Anhui Province are divided into three specific indicators: psychologist Chales Spearman in 1904. The basic idea is to first group variables according to the size of correlation so that the variables in the same group Correlation is high, and the correlation of different groups of variables is low. Each group of variables represents a basic structure, and then through analysis of the factor load matrix, etc., according to the size of the variance contribution rate, several common factors that can cover a large number of original data Build a factor model to decompose the original observation variables into a linear combination of factors, and finally evaluate the research object based on the comprehensive score. This method is widely used in comprehensive evaluation in many fields such as society, natural sciences, and economic management. The basic model is as follows. business income (10000 yuan), total industrial output value (10000 yuan), total export value (10000 US dollars); input capacity, including four specific indicators: total fixed assets investment (10000 yuan), total infrastructure investment The amount of foreign investment actually utilized (USD 10000), the amount of foreign investment actually utilized (RMB 10000); the innovation ability, including two specific indicators: the number of patent applications (PCS), the number of patent authorizations (PCS). There are 9 secondary indicators in total, as shown in Table 1.

The data in this paper comes from the 2018 Anhui statistical yearbook, which collates the data of the above nine indicators of 11 development zones. Spss22.0 software is used for data processing. Firstly, kmo and Bartlett are used to test the original data to confirm whether principal component analysis can be done; secondly, standardization is carried out to eliminate the influence of different dimensions; finally, principal component analysis is carried out for the standardized data.

Table 1 evaluation indexes of development capacity of development zones above provincial level in Anhui Province

\begin{tabular}{clc}
\hline First level indicators & \multicolumn{1}{c}{ Secondary level indicators } & Variable symbols \\
\hline \multirow{3}{*}{ output capacity } & $\begin{array}{l}\text { Operating income of enterprises in the whole } \\
\text { district (10000 yuan) }\end{array}$ & $\mathrm{X} 1$ \\
& Total industrial output value (10000 yuan) & $\mathrm{X} 2$ \\
& Total exports (USD 10000) & $\mathrm{X} 3$ \\
& Total investment in fixed assets (10000 yuan) & $\mathrm{X} 4$ \\
& Total investment in infrastructure (10000 yuan) & $\mathrm{X} 5$ \\
& Actually utilized foreign investment amount (USD & $\mathrm{X} 6$ \\
& $10000)$
\end{tabular}


Actual investment outside the province (10000 yuan)

$\mathrm{X} 7$

Number of patent applications (PCS) $\quad \mathrm{X} 8$

innovation capacity

Patent authorization (PCS)

$\mathrm{X} 8$
$\mathrm{X} 9$ generally performed first. Spss 22.0 software is used to test the original data of 9 indicators in 11 development zones in 2017. From the output results (see Table 2), kmo statistics is $0.713>0.6$; Bartlett's sig value of sphericity test is $0.000<0.005$, so the indicator data is suitable for principal component analysis

In order to verify whether the data can be used for principal component analysis, kmo and Bartlett tests are

Table 2 Kmo and Bartlett test

\begin{tabular}{ccc}
\hline Kaiser-Meyer-Olkin & & 0.713 \\
Bartlett's sphericity & Approximate chi & 118.372 \\
test & square & 36 \\
& df & 0.000 \\
\hline
\end{tabular}

\subsection{Extraction of common factor}

Using spss22.0 as principal component analysis, the eigenvalues of correlation coefficient matrix and corresponding eigenvectors are calculated, and then As for the variance percentage of principal component interpretation, the calculation results are shown in Table 3. Common factors are extracted according to the principle of eigenvalue greater than 1 . It can be found that the initial score eigenvalues of the first two common factors are6.358 and 1.366 which are greater than 1 , and the initial eigenvalues of the other nine common factors are less than 1 , and the cumulative contribution rate of variance of the two common factors is $70.642 \%$ and
$15.172 \%$, respectively. The sum of the cumulative contribution rate of variance is up to 85.814 , far more than $70 \%$ of the basic requirements, indicating that the first two common factors can well reflect the information of 9research indicators, so the first two common factors can be extracted, respectively the main components $F_{1}$, $F_{2}$.

In order to better show the effect of common factor extraction, Kaiser standardized orthogonal rotation is adopted in spss22.0, and convergence is achieved in three iterations, The principal component $F_{1}, F_{2}$ See Table 4 for the load on each research index, and classify according to the load value of index factor $>0.5$.

Table 3 Total variance of interpretation

\begin{tabular}{ccccccc}
\hline & \multicolumn{3}{c}{ Initial eigenvalue } & \multicolumn{3}{c}{ Sum of load squares } \\
\cline { 2 - 6 } Factor & Total & $\begin{array}{c}\text { Variance } \\
\text { percentage }\end{array}$ & Cumulative $\%$ & Total & $\begin{array}{c}\text { Variance } \\
\text { percentage }\end{array}$ & Cumulative $\%$ \\
\hline 1 & 6.358 & 70.642 & 70.642 & 6.358 & 70.642 & 70.642 \\
2 & 1.366 & 15.172 & 85.814 & 1.366 & 15.172 & 85.814 \\
3 & 0.667 & 7.407 & 93.221 & & & \\
4 & 0.302 & 3.356 & 96.577 & & \\
5 & 0.167 & 1.853 & 98.429 & & \\
6 & 0.124 & 1.380 & 99.810 & & \\
7 & 0.008 & 0.090 & 99.900 & & \\
8 & 0.007 & 0.074 & 99.974 & & & \\
9 & 0.002 & 0.026 & 100.000 & & & \\
\hline
\end{tabular}




\begin{tabular}{|c|c|c|}
\hline \multicolumn{2}{|c|}{$\begin{array}{l}\text { Extraction method: principal component analysis. } \\
\text { Table } 4 \text { Factor load matrix a after rotation }\end{array}$} & \\
\hline \multirow{2}{*}{ Variable } & \multicolumn{2}{|c|}{ Factor } \\
\hline & $F 1$ & $\mathrm{~F} 2$ \\
\hline $\mathrm{X} 1$ & 0.948 & -0.023 \\
\hline $\mathrm{X} 2$ & 0.931 & 0.085 \\
\hline $\mathrm{X} 3$ & 0.883 & 0.056 \\
\hline $\mathrm{X} 4$ & 0.133 & 0.518 \\
\hline X5 & 0.141 & 0.603 \\
\hline X6 & -0.196 & 0.553 \\
\hline X7 & -0.066 & 0.959 \\
\hline X8 & 0.932 & -0.160 \\
\hline X9 & 0.934 & -0.021 \\
\hline
\end{tabular}

Extraction method: main analysis. Rotation method: orthogonal rotation with Kaiser standardization. a. It converges in three iterations.

The principal component $F_{1}$ is used to explain the indicators such as business income (X1), total industrial output (X2), total export (X3), patent application (x8) and patent authorization (X9). It can be found that these indicators are the output of the Development Zone, so the principal component can be defined as the output capacity of the development zone.

The main component $F_{2}$ is used to explain the total fixed asset investment (X4), total infrastructure investment (X5), actual foreign investment (X6), and actual investment outside the province (X7). These indicators are the fixed asset investment, infrastructure construction investment, attracting foreign and domestic investment in the development zone. Therefore, the main component can be defined as the investment capacity of the development zone.

\subsection{Calculation factor score}

According to the expression (3), (4) and (5) of principal component function, calculated the scores of principal component $F_{1}, F_{2}, F$ in 2009-2018by Excel software, See Table 5 and figure 1 for details.

$$
\begin{array}{r}
F_{1}=0.948 X_{1}+0.931 X_{2}+0.883 X_{3}+\cdots+0.934 X_{9}(3) \\
F_{2}=-0.023 X_{1}+0.085 X_{2}+0.056 X_{3}+\cdots-0.019 X_{9}(4) \\
F=\left(0.70642 F_{1}+0.15172 F_{2}\right) / 0.85814\left(\zeta_{5}\right)
\end{array}
$$

According to table 5 and figure 1 , on the whole, it can be found that the output capacity, input capacity and comprehensive capacity of 11 development zones in 2017 are weak, the stronger ones are Hefei high tech Industrial Development Zone, Hefei Economic and Technological Development Zone and Wuhu Economic and Technological Development Zone, because the $F_{1}$, $F_{2}, F$ scores of these development zones are significantly higher than those of other development zones.
First, according to the $F_{1}$ score distribution of output capacity, there is a big difference between development zones. There are only three development zones with positive scores, namely, Hefei Economic and Technological Development Zone, Hefei high tech Industrial Development Zone and Wuhu Economic and Technological Development

Zone. Other development zones have negative scores. The scores of Hefei Economic and Technological Development Zone, Hefei high tech Industrial Development Zone and Wuhu Economic and Technological Development Zone ranked first to third are quite different from those of other development zones, which shows that the three development zones have strong output capacity, because they are located in the economically developed cities of Hefei and Wuhu and have certain regional advantages. Second, according to the $F_{2}$ score distribution of investment capacity, the investment capacity of Hefei and Wuhu development zones is still in the forefront. 11 development zones can be divided into three levels, including Hefei high tech Industrial Development Zone, Hefei Economic and Technological Development Zone and Wuhu Economic and Technological Development Zone with scores greater than 1; MAANSHAN economic and Technological Development Zone, Bengbu high tech Development Zone, Wuhu high tech Development Zone, Chuzhou economic and Technological Development Zone and Chuzhou economic and Technological Development Zone with scores between 0 and 1 There are Tongling Economic and Technological Development Zone, Ma'anshan high tech Development Zone and Chizhou economic and Technological Development Zone less than 0.From the distribution of comprehensive ability $F$ scores, only Hefei high tech Industrial Development Zone, Hefei Economic and Technological Development Zone and Wuhu Economic and Technological Development Zone have positive scores, among which the comprehensive ability scores of development zones are all negative, indicating that most 
of the development zones in Anhui Province have weak development ability.

Table 5 output capacity, input capacity and comprehensive score of each development zone

\begin{tabular}{ccccccc}
\hline Zones & F1 & Ranking & F2 & Ranking & F & Ranking \\
\hline Hefei hi tech zones & 6.88 & 2 & 1.28 & 2 & 5.89 & 2 \\
Hefei economic zones & 8.96 & 1 & 1.37 & 3 & 7.61 & 1 \\
wuhu economic zones & 3.65 & 3 & 2.70 & 1 & 3.48 & 3 \\
wuhu hi tech zones & -0.49 & 4 & 0.33 & 6 & -0.35 & 4 \\
Bengbu hi tech zones & -3.00 & 9 & 0.47 & 5 & -2.39 & 7 \\
Maanshan economic zones & -3.12 & 10 & 0.80 & 4 & -2.43 & 8 \\
Maanshan hi tech zones & -2.98 & 8 & -1.13 & 9 & -2.65 & 10 \\
Tongling economic region & -2.15 & 6 & -0.37 & 8 & -1.84 & 6 \\
Aaqing economic zones & -2.47 & 7 & -2.29 & 10 & -2.44 & 9 \\
Chuzhou economic region & -1.41 & 5 & 0.32 & 7 & -1.10 & 5 \\
Chizhou economic zones & -3.86 & 11 & -3.47 & 11 & -3.79 & 11 \\
\hline
\end{tabular}

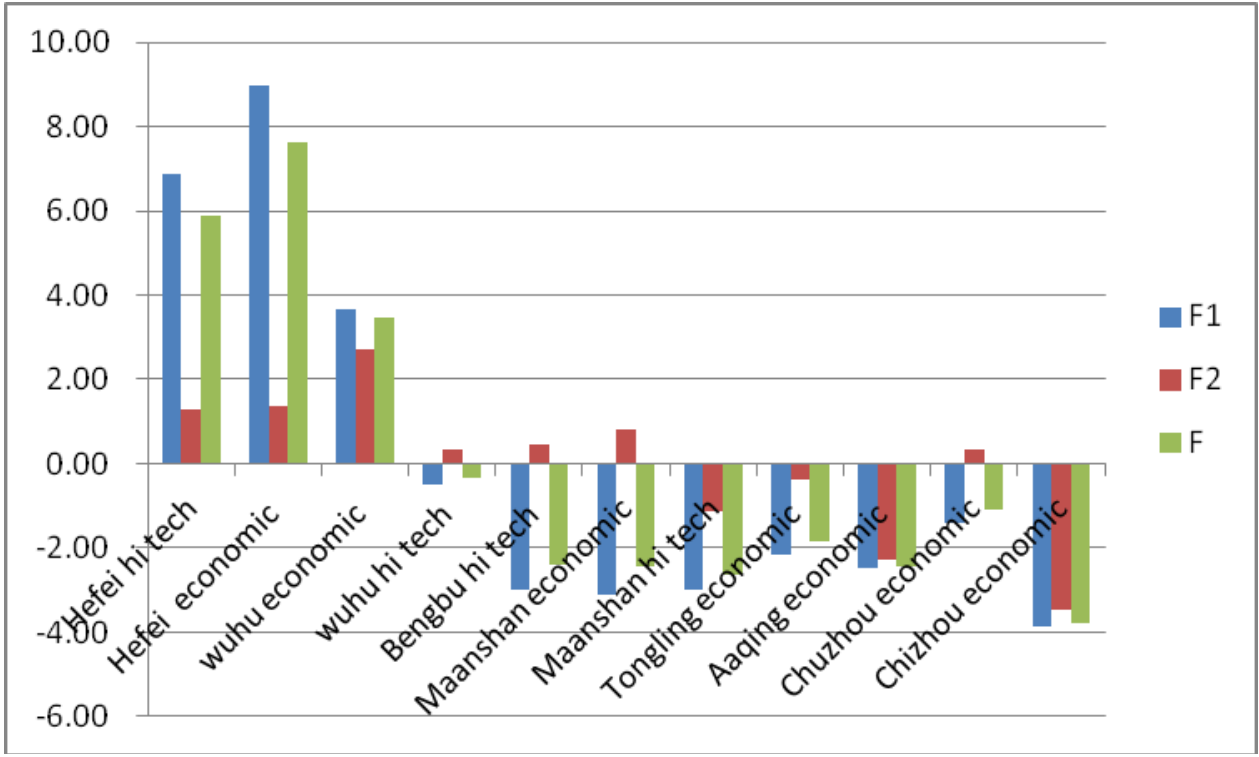

Figure 1 change trend of output capacity, input capacity and comprehensive capacity scores of each development zone

\section{CONCLUSIONS AND SUGGESTIONS}

In this paper, the principal component analysis method is adopted to measure the output capacity, input capacity and comprehensive development capacity of 11 development zones above the provincial level in anhui province in 2017, taking 9 indicators reflecting the development capacity of development zones in anhui province as the research object. The results show that Hefei high tech Industrial Development Zone, Hefei Economic and Technological Development Zone and Wuhu Economic and Technological Development Zone all have high scores in output capacity, input capacity and comprehensive development capacity, while other development zones have low scores, most of which are even negative. Two conclusions can be drawn: first, the development capacity of the development zones in Anhui Province shows a trend of polarization, the stronger the stronger, the weaker; second, the overall development capacity of the development zones in Anhui Province is not high, because the scores of most of the development zones are negative. According to the above research results, in order to improve the development ability of the Development Zone in Anhui Province, first of all, give priority to the development of high-tech industries with high added value, which can effectively improve the output ability of the development zone; second, reduce the traditional investment in fixed assets, increase the investment in scientific and technological innovation, optimize the input structure, and effectively improve the 
input-output efficiency of the development zone; third, promote the development The transformation and upgrading of the zone, breaking away from the past dependence on traditional production factors and modes of production, and realizing the innovation and upgrading of the development zone can improve the overall capacity of the Development Zone in Anhui Province.

\section{ACKNOWLEDGMENT}

This work was supported by 2017 excellent and top talents cultivation project of Anhui Province (Grant No. gxyqZD2017077)

\section{REFERENCES}

1. Zhang Lan. Evaluation of the industrial development level of Hubei high tech Development Zone[J]. Statistics and decision, 2015 (3): 55-57.

2. LEI Shuguang. Performance Evaluation and Transformation Development of Shanghai Development Zone[J]. Shanghai Management Science, 2017(12): 70-75.
3. WANG Cheng-jiang. Evaluation on development potential of State-level economic and technological development zone-Empirical research Based on the anhui province economicand technological development zone[J]. Scientific Management Research, 2013(2): 71-74.

4. ZHANG HenG, GUO Ya. Research on Dynamic Development of Economic Development Zones Based on Times Series Analysisi \& PCA-Take the example of several economic development zones in anhui province $[\mathrm{J}]$.Science Technology and Industry, 2013 (3): 5-7.

5. CAO Cheng-long. Development Level Evaluation of Development Zones Based on the Methods ofEntropy Weight and Clustering Analysis-A Case Study of Anhui Province[J]. Journal of Southwest University of Soience and Technology, 2018(12): 56-61.

6. WANG Xiao-men.Research on Evaluation and Transformation of Anhui Province Economic Development Zone[J]. JOURNAL OF CHONGQING JIAOTONG UNIVERSITY (Social Sciences Edition, 2018(2): 75-79. 